\title{
On the Sources of Interlanguage Phonology: Some Evidence from Yoruba-English
}

\author{
Raphael O. Atoye. \\ Obafemi Awolowo University
}

\begin{abstract}
In recent research, it is claimed that deviant features of interlanguage grammars arise only from the users' knowledge of the rule system of the target language. This paper examines the relative contribution of the rule system of each of the target language, the native language and of universal tendencies to a deviant aspect of Yoruba-English phonology. It concludes that the native language is the major source of deviance in the aspect of Yoruba-English investigated.
\end{abstract}

\section{Introduction}

In her analysis of Spanish English (SE), Mairs concludes that the deviant stress pattern of that interlanguage derives from the stress rules of "standard" English. Mairs' conclusion is based on her working assumption expressed in her introductory passage in the following words:

When second language learners from a common language background produce the same approximations of target language forms, it may be assumed that they are using the same rules to generate these forms, and that these rules are based upon linguistic knowledge (conscious or otherwise) available to all of them. Furthermore, according to current second language acquisition theory, both correct and incorrect forms are generated by the same set of rules-the interlanguage grammar.

After a thorough analysis of word stress in SE, Mairs, in apparent loyalty to "current second language acquisition theory," concludes as follows:

While stress systems based on universal tendencies or on the Spanish speakers" native language stress rules did not appear to account for the interlanguage data, it was determined that all of the stress patterns that did occur in the data can be generated by 
the target language stress system, given the independently motivated condition on rule application formulated in the Marked Rime Hypothesis.

An examination of a similar aspect of the grammar of the English of native speakers of Yoruba, (a language spoken in south-western Nigeria), as will be shown in the present essay, does not support the current second language acquisition theory referred to by Mairs. The findings in the present study lead to the following three conclusions: (1) speakers of an interlanguage (IL) from the same language background use the same rules to generate common deviant forms; (2) these rules are based upon linguistic knowledge commonly available to the speakers; (3) the incorrect forms are generated mainly by the rules of the speakers' native language. Since the third conclusion contradicts the current second language acquisition theory underlying Mairs' findings, it will be the focus of the analysis of the Yoruba-English (YE) data carried out in the present study.

\section{The Nature of IL Grammars}

The grammar of a language is the set of rules on which that particular language is organized. The term "interlanguage" (Selinker; also "learners' approximate systems," Nemser) denotes the linguistic system used by learners/users of a second language. It is coined in recognition of the fact that such a system differs both from that of the target language (the one being learned) and that of the source language (the learners' own mother tongue). For example, it has been shown that the rule system of Nigerian English differs from that of the English used by the British, American or Australian native speakers of the language (Amayo; Atoye "Word Stress"). The term "New Englishes" reflects the existence of observable differences amongst English interlanguages such as Yoruba-English, IndianEnglish, Spanish-English, French-English and a host of other non-native Englishes.

It is however necessary to emphasize the fact that the difference between English and any of its various interlanguages is partial rather than total. As observed by Gatbonton the grammar of any interlanguage is a mixture of both target language and non-target language forms, which in plain language, means that it is a mixture of correct and incorrect forms. When discussing interlanguage grammars, however, linguists traditionally concern themselves with the deviant, non-target language forms, the target language forms being taken for evidence of mastery through successful learning or positive transfer, as the case may be. In keeping with that tradition, I will concern myself only with the deviant aspect of YE word stress in this essay.

\section{The Data}

Two sets of data are presented for the subsequent analysis. The data on YE is taken from the corpus analyzed in an earlier study (Atoye "Word Stress"). It was collected at various times and locations, in Ile Ife city, Osun State, Nigeria, including the Obafemi Awolowo University situated a few kilometers outside the city. It represents, very fairly, the 
pronunciation of the word types exemplified in the list by highly educated Yoruba speakers of English, including university academic staff. The data on Yoruba consists of samples (taken from Atoye "Tone Structure") illustrating the tone (voice pitch) structure in bisyllabic words. As Yoruba does not impose any constraint on the co-occurrence of tone, all the nine potential tone configurations are exemplified in the data. The data is restricted to bisyllabic words because, as observed in the earlier study, Yoruba simple words seldom exceed two syllables. The numbers in front of each word indicate its tone structure, with 1 for the highest (acute), 2 for mid (level) and 3 for low (grave) tone. The words in both lists are organized into relevant classes for ease of reference. $V$ stands for vowel, $\mathrm{C}$ for consonant, $\mathrm{N}$ for nasal and $\mathrm{VG}$ for vowel glide.

A raised vertical stroke before a syllable indicates that the syllable is assigned primary stress. Later in the analysis, a similar sign is often employed to indicate a high tone syllable in Yoruba which is therefore sometimes referred to, rather unconventionally, as primary tone. Phonemic transcription is not used as it would add no useful information.

\subsection{Wrongly stressed words in YE}

\subsubsection{Words stressed on a Marked Rime (MR)}

(a) -VG Words: ba'rrier, codi'fy, digni'fy, ca'reer, magni'fy, justi'fy, inter'view, personi'fy, intensi'fy

(b) -VGC words: recog'nize, adver'tize, pur'chase, civi'lize, exer'cise, ope'rate, contri'bute, contemp'late, ago'nize, dedi'cate, calcu'late, edu'cate, uri'nate, ele'vate, super'vize, demon'strate, compli'cate, drama'tize

(c) -VG, -VGC +stress-neutral suffix (derived from [a] and [b]): justi'fying, magni'fier, digni'fying, ele'vator, super'visor, calcu'lator, edu'cator, attri'buted, uri'nating, adver'tising, recog'nizing, refrige'rator, trans'lator, urba'nize, urba'nizing

(d) -VN, -CN -VGN words: bulle'tin, io'dine, chloro'quin, tele'phone, tele'vision, per'fume, ur'ban, ma'dam, cathe'rine, aspi'rin, reso'chin, noval'gin, niva'quin, valen'tine, vac'cin

(e) -VC, -VCC words: com'bat, pe'trol, inte'rest, broad'cast, compre'hend, imple'ment, ta'rrif, repri'mand, bap'tist, co'lleague, cala'bash, cater'waul

3.1.2. Words with multiple MR: broad'cast, bull'doze, compre'hend, congratu'late, com'bat, emba'rrass, con'tour, ho'spital, circum'stances, mush'room, bis'cuit

3.1.3. Words wrongly stressed but not on MR: cri'ticism, com'bative, bar'barism, trans'fer, capi'talism, co'mmunism, co'rrigible, ma'nnerism, anta'gonism

3.1.4. Words without MR: ce'remony, ca'tegory, cater'pillar, pa'mela, archipe'lago, ca'lendar, ce'libacy 


\subsection{Tone structure in bisyllabic Yoruba Simple Words}

sibi - 11 (spoon); jade - 12 (go out); tule - 13 (student); ile - 21 (house); omo - 22 (child); oja - 23 (market); iya - 31 (mother); orun - 32 (heavens); igo - 33 (bottle)

\section{Sources of Deviance}

\subsection{Target language rules}

In tracing the source of deviant word stress in SE to the target language, Mairs appeals to the English stress system of metrical analysis proposed by Hayes. She contends that SE speakers misapply the LVS (long vowel stressing) rule in that they assign primary stress to the rime containing the long vowel (vowel glide or VG) instead of assigning it to the rime of the syllable to its left. As a result, words containing syllables with -VGC rimes are wrongly stressed on those -VGC rimes. Syllables containing such rimes followed by a stress-neutral suffix are similarly stressed. Examples in the YE data include all word-final -VG, -VGC rimes in 3.1.1 (a) and (b) above: ba'rrier, magni'fy, signi'fy, agi'tate, exer'cise. $-\mathrm{VGC}+$ stress-neutral suffix words are exemplified in 3.1c above. With the exception of -VC, -VCC, -VG and -VG + stress-neutral words in the YE data, all the other word types also occur in Mairs'SE data, a significant correspondence as will be seen later. Of interest, also, is the fact that almost all the words in the SE correct list are correctly stressed by YE speakers, the only exceptions being the following six words pronounced in YE as ave'nue, berbe'cue, maga'zine, quali'fy, tele'phone and diff' 'culty; all wrongly stressed on a rime that is marked for the Yoruba speakers.

It is, however, not possible, to explain the YE data within a metrical analysis of English stress rules as proposed by Mairs-by way of complex rule modifications aimed at preventing the rules of rime extrametricality "from applying in words that end in -VGC on the first cycle" but making them "yet still play a role in the derivation of words of other structural types." Unfortunately, the complex rule modifications proposed by Mairs violate the simplicity metric, a condition of universal tendencies in language acquisition. Their complexity is acknowledged by Mairs herself in the following passage:

It is worth asking, for example, whether a stress system in which the rules of rime extrametricality do not apply to words ending in -VGC on the first cycle could be considered more simple and/or less marked than the English stress system. However, because such a system would require an additional distinction to be made between rime configurations before certain rule applications, it would be more complicated, not less.

It is an accepted second language acquisition theory that learners tend to simplify, not complicate, the rules of their target language. Any rule modification resulting in rules that are more complex than the natural rules of the target language could not have been a product of the learners' limited knowledge or intuition. We therefore reject Mairs' proposed target language rule modification in accounting either for the SE or the YE data, 
or for any second language acquisition data. Having rejected the complex target rule modification discussed above, Mairs appeals to the markedness theory, which, as will be shown in section 4.2 below, accounts for much of the YE data and of Mairs' SE data. The major flaw in markedness, however, is that, contrary to Mairs' assumption, it is not independently motivated in the context of second language acquisition. Mairs also admits that fact as will be clearly shown in section 4.2 below. Such an assumption is one of the theoretical fallacies underlying the current second language acquisition theory that equates second language acquisition with first language acquisition. Even if markedness were independently motivated, it is a feature of universal tendencies rather than of target language rules, a fact implied later on in Mairs' essay. Markedness may be employed to explain second language data but not as a feature of the target language rule. In other words, the attempt to explain the data by way of target language rules fails right at the theoretical level, for once we invoke the marked rime hypothesis in second language acquisition, we are no more operating within the confines of the target language rules. Let us therefore examine the role of markedness as a feature of universal tendencies in relation to the YE data in section 4.2 below.

\subsection{Universal tendencies}

Close examination of both the YE data (and Mairs' SE data) very strongly supports the view that the -VGC (+stress neutral suffix) final rime is wrongly stressed because it is marked for the Yoruba as well as for the Spanish speakers. The preferred syllable structure in Yoruba is CV. V is possible, even common, in word-initial syllables only: ojo: 33 (rain), owo: 21 (money). There is no vowel glide, though there are vowel sequences belonging to different syllables. The admissible syllable structure is therefore $(\mathrm{C}) \mathrm{V}$ while the only permissible rime is $-\mathrm{V}$ in all positions. The - VGC rime is therefore highly marked for the Yoruba. Similarly, according to Mairs, quoting Harris (16) the rime configuration -VGC (+stress-neutral suffix) is marked for the Spanish speakers as it occurs only once in Spanish: in auxilio, regarded by Harris as an "extrasystematic oddity" in the language.

Now, if the word-final rime -VGC is marked both for the Yoruba and the Spanish speakers, and both sets of speakers wrongly stress words on that same marked rime, then a very strong case is made for markedness and we are compelled by the facts to acknowledge its influence. Tentatively, then, one concludes that speakers of Yoruba and speakers of Spanish (and probably speakers of other languages) wrongly stress English words that contain rime configurations that are marked for them.

The case for markedness is further strengthened by an additional observation in respect of the Yoruba speakers. The YE data contains words having -VG (+stress-neutral suffix) $-V G N$ and $-V N$ word final rimes that are also wrongly stressed on these marked rimes. Examples from sections 3.1.1c and d above include digni'fy, ba'rrier (-VG); bulle'tin, maga'zine (-VN); io'dine, magni'fying (-VGN); and ma'dam, ur'ban (CN).

There is yet another class of words, wrongly stressed in YE, (see 3.1.1 [e]) which contain rime configurations that are alien to and are therefore marked for Yoruba speakers. Those rimes are exemplified in pe'trol, com'bat (VC); compre'hend, broad'cast (VCC). These examples further support markedness. Markedness does not, however, account for 
all the word types wrongly stressed in $\mathrm{YE}$ as indicated in the data. Three types are yet to be accounted for: they are words with multiple MR (in 3.1.2 above), words not stressed on MR (3.1.3) and words without MR (3.1.4).

Each of the words in the first type contains more than one marked rime, yet only one of them is wrongly stressed. Examples include broad'cast (VC/VCC), congratu'late (VC/V/V/VGC), emba'rrass (VC/V/VC), and con'tour (VN/VG). The second type consists of words which contain a marked rime but are wrongly stressed on a familiar, unmarked rime rather than on the marked rime. They are exemplified in 3.1.3 and include hos'pital (VC/V/CV), com'bative (VC/V/VC) and capi'talism (V/V/V/VCC). Words in the third group do not contain any marked rime but are, nevertheless, wrongly stressed in YE. Examples in 3.1.4 include ce'remony $(\mathrm{V} / \mathrm{V} / \mathrm{V} / \mathrm{V})$ and ca'tegory $(\mathrm{V} / \mathrm{V} / \mathrm{V} / \mathrm{V})$.

Before summarizing, let us examine a couple of words in relation to the MRH. If we assume that YE speakers mis-stress ur'ban because it has, for them, a -VN marked rime, they should equally wrongly stress 'organ as it, also, has a -VN marked rime. But, contrary to the prediction of the MR hypothesis, they stress 'organ correctly on the word-initial syllable. The same speakers, however, wrongly stress both urba'nize and orga'nize on the word-final syllable. In urbani'zation and all -ation words, where the stress is as near the word-final position as possible, there is no instance of wrong stressing in $\mathrm{YE}$. Consequently, YE speakers wrongly stress words such as calcu'late, calcu'lator, edu'cate, edu'cator, which are normally stressed on the word-initial syllable, (i.e. far from the word-final position), while they correctly stress edu'cation, calcu'lation, $i$ 'gnition and other -tion words near the word final syllable. It is also possible that the YE pronunciation of calcu'late and calcu'lator is derived, through back formation, from their -tion form, calcu'lation, In that case, the stress error would be attributed, not to interlingual, but to intralingual transfer.

In summary, the data in 3.1.1 (a)-(e) lends support to the MR hypothesis but the one in 3.1.2-4 does not. The marked rime hypothesis therefore fails to account for all the wrongly stressed words in YE and, one suspects, in SE too. We are obliged, therefore, to consider other sources of that interesting feature of YE in particular, and of SE and other English interlanguages in general.

\subsection{Native language rules}

Comparing Yoruba with English is not as easy as comparing Spanish with English-both English and Spanish are stress languages while Yoruba is a tone language. The problem is, however, not insurmountable. It has been argued (Atoye "African Languages") that tone is the phonetic counterpart of stress (not of intonation) with which it should be more appropriately compared and employed in classifying the world's languages into synchronic voice pitch types. We should therefore be talking about tone vs. stress languages, not of tone vs. intonation languages. Tone is the voice pitch equivalent of stress and they are both similarly calibrated in terms of pitch height as High, Mid and Low. They are mutually convertible, the only difference being that tone is phonemic in tone languages while stress is, generally, not phonemic in the stress languages. 
Close analysis of pitch structure in Yoruba simple words, (Atoye "Tone Structure") suggests that high (acute) tone, the pitch equivalent of primary stress, is rarely assigned to the initial syllable, the preference being the ultimate or the penultimate syllable. Yoruba simple words, as revealed in that analysis, do not normally exceed two syllables, the ultimate syllable being almost always assigned acute (primary) tone as shown in 3.3 above. Examples are $i^{\prime} y a: 31$ (mother), i'le: 21 (house), and $b a^{\prime} b a: 31$ (father). A few bisyllabic words assigned primary tone on the initial syllable are assimilated English loan words such as 'titi: 13 (street), 'moto: 13 (motor), and 'si'bi: 11 (spoon). Many other examples cited by Olorode include 'baba: 13 (barber), 'dereba: 113 (driver), 'beba: 13 (paper), and miliiki: 1133 (milk). These words are derived from their English sources through various consonant cluster simplification processes such as vowel insertion and/or consonant insertion and deletion. They are exceptions to the general rule.

Trisyllabic words are not listed in the data here (but see Atoye "Tone Structure" for samples) because they are all morphologically complex. Even then, those of them assigned acute tone on the initial syllable are sentence translations as is observable from their English glosses, e.g. yejide: 111 (mother has come back i.e. reincarnated; the name given to a female child born soon after the death of her paternal or maternal grandmother). In contrast, the majority of them, assigned primary (acute) tone on the penultimate or ultimate syllable, are phrasal expressions derived through affixation, such as akowe: 231 (writer of book [ $a$ : nominalizimg morpheme]), $k o$ (write), iwe (book, with the morpheme-initial vowel harmonized with the preceding one, and subsequently deleted) to derive akowe (secretary). In brief, the tendency in Yoruba indigenous simple words is to assign acute (high or primary) tone to the ultimate or penultimate syllable, thus avoiding it on the initial one.

Now, more detailed examination of the YE data shows that a similar tendency to avoid primary stress on the initial or on a relatively early syllable in the word is dominant. None of the words in the YE data is stressed on the initial syllable. Any word stressed on the initial syllable in native-speaker English has its primary stress automatically transferred to a later syllable in the word, a process termed progressive stress shifting (Atoye "Word Stress"). This similarity between the word stress tendency in Yoruba and in YE cannot be accidental. It argues very strongly in favour of linguistic transfer. The Yoruba speakers appear to have transferred the rules of the pitch system of their native language to the pitch system of their English interlanguage. It is, in fact, not only the tendency to assign a high pitch to a later syllable that is so transferred. As observed by Amayo, wholesale transfer of the entire tone systems of Nigerian languages characterize what that writer refers to as "tonal English." Similarly, the Spanish stress system analyzed by Harris (85), which Mairs employs in her own analysis, shows that Spanish does not generally assign primary stress to a word-initial or an early syllable in polysyllabic words. Mairs summarizes that tendency as follows: "The basic generalization for assigning stress in Spanish pronunciation is that consonant-final words have primary stress on the final syllable (mu'jer 'woman, wife') and vowel-final words have primary stress on the penultimate syllable ( dis'tinto 'distinct')."

The same tendency to stress a relatively late syllabe in the word is observable in the wrongly stressed words in Mairs' SE data, indicating that the Spanish word stress rule 
actually provides the underlying principle for the SE word stress rule observed by Mairs. It would appear that syllable position in the word, rather than syllable-rime type, as Mairs concludes, determines deviant word stress in SE. What is required to unravel that fact is a "deeper contrastive study" of the type advocated by James. Considering the similarity observed between the SE and YE dati, and that between Spanish and Yoruba with respect to the assignment of primary stress/tone, a fourth conclusion may be reached from the analysis in the present study as follows: when speakers from different but similar language backgrounds produce similar interlanguage approximations, it may be assumed that they are using similar rules to generate those forms, and that those rules are based on similar linguistic experience shared by them-a similar subsystem of their respective native language rules.

Finally, we conceded the partial influence of markedness in 4.2 above. It is now time to reconcile the role of markedness with that of the native language in shaping the rules of an interlanguage grammar. Markedness, referred to as an independently motivated factor by Mairs, is, in fact, dependent on the speakers' previous linguistic experience. A linguistic feature is marked for a group of speakers if it is not already familiar to them through their native language grammar, or the grammar of another interlanguage previously acquired by them. Commenting on the rimes that are marked for speakers of Spanish, Mairs, herself, acknowledges that connection very clearly in the following words: "If these rimes are ungrammatical in their mother tongue, then it is reasonable to assume that Spanish speakers consider them marked."

It is clear from this short explanation that markedness, in the sense in which Mairs employs it, is an indirect transfer of the speakers' native language grammar. Markedness, therefore, supports the native-language grammar theory, not the target-language grammar hypothesis. Even if markedness were accepted as an independently motivated factor, the stress shifting rule proposed here would still be more powerful in accounting for the YE data. The latter accounts for more varied data as is borne out by the analysis presented above. Markedness fails to account for the data in 3.1.2, 3.1.3 and 3.1.4 whereas stress shift accounts for all the data, from 3.1a to 3.1.4. In addition, it is noteworthy that all the words in 3.1.1 (a)-(e) are stressed on a word final marked rime, or on a penultimate marked rime if the word contains a stress neutral suffix. This is not likely to be due to sheer co-incidence. Similarly, words in the data that contain two or more marked rimes are generally wrongly stressed on the one that is farthest from the word-initial position. The influence of the marked rime, if it has any, is subsumed under that of the native language grammar. One can safely conclude, in the light of the available evidence that the deviant stress pattern observed in YE reflects the transfer of the organizing principles of the tonal system of the speakers' native language to their English interlanguage.

\section{Conclusion}

Perhaps one of the greatest problems confronting linguists in the search for the sources of deviant interlanguage forms is their refusal to acknowledge the fact that an error might be traceable to more than one source, and more importantly, that errors in different aspects 
of the grammar of an interlanguage may arise from different sources. Such a multiple-source view of interlanguage errors holds that any number or type of sources may, jointly or severally, contribute to an interlanguage grammar. As Odlin (127) observes, "transfer is not the only factor affecting the ease or difficulty of reproducing target language sounds." As that author further explains, "typological and apparently universal factors sometimes operate independently of transfer and sometimes operate together with it." Intralingual transfer (Jain) also plays a role in giving rise to developmental errors. In brief, the grammar of an interlanguage is a mixed bag of subsystems influenced by factors as diverse as the model to which learners are exposed, the target language rule, the native language rule and universal tendencies. All the considerations above notwithstanding, the supremacy of the influence of the native language grammar cannot be gainsaid. Selinker, in one of the most important articles on second language acquisition strategies ("Earliest Experimental Records"), upholds the supremacy of the influence of the native language grammar while acknowledging the multifarious sources of interlanguage grammar. Selinker concludes that article in the following words:

Thus, it is now possible to view the creation of IL as a process reflecting (universal) hypotheses about the L2 input, as well as a process of selectively using NL knowledge and other ILs known to the learner. These general sorts of processes must intersect in some as yet unknown way, universal grammar scholars seeing universal processes as prime; but arguments that see language transfer as prime, at least on some occasions, underlie what is presented in this paper. It is far from settled.

One would also like to recall the implicit warning by Sridhar quoted in an equally authoritative article by Nickel as follows:

Thus one sees a tendency in the current literature to downplay the role of first language interference, and an overeagerness to explain away what seem to be patently interference errors in terms of some other strategy felt to be more respectable or more consistent with the view of the target language learner as an active experimenter with language.

That "current second language acquisition theory," on which Mairs' analysis of the SE data is modelled, is clearly a victim of that tendency. Sridhar rightly recognizes the need to include the other "components besides interlingual interference in the explanatory account of target language learners' performance," but rightly insists that contrastive analysis "still remains the most rigorously worked-out component of the theory." Nickel agrees with that writer and the reason, I believe, is that the native language grammar is, naturally, the most influential of all the known sources of deviant aspects of interlanguage grammars. That is what the analysis carried out in the present essay suggests. Classical conirastive analysis (CA) as proposed by the founding fathers (Fries; Weinreich; Lado; etc.) may have overshot its limits in striving to account for all deviant interlanguage forms 
in terms only of the influence of the learners' native language. Nevertheless, any "current second language acquisition theory" seeking to diminish the contribution of the learners' native language to those forms ignores available interlanguage data.

\section{Works Cited}

Amayo, Airen. "Tone in Nigerian English." Paper presented to the Sixteenth Regional Meeting of the Chicago Linguistics Society. Chicago, 1981.

Atoye, Raphael O. "African Languages as just Tone and Not Intonation Languages?" Epasa Moto: A Bilingual Journal of Language, Letters and Culture 1.1 (1989): 1-14.

. "Tone Structure in Yoruba Simple Words." Paper sent to the 20th Annual Conference on African Linguistics (ACAL), Urbana Champagne, 1989.

. "Word Stress in Nigerian English." World Englishes 10.1 (1991): 1-6.

Fries, C. C. Teaching and Learning English as a Foreign Language. Ann Arbor: Michigan University Press, 1945.

Gatbonton, Elizabeth S. "Systematic Variation in Second Language Speech." Unpublished Ph.D. thesis. McGill University, 1975.

Harris, J. W. Syllable Structure and Stress in Spanish: A Nonlinear Analysis. Cambridge: MIT Press, 1983.

Hayes, B. P. A Metrical Theory of Stress Rules. Ph. D. thesis. Yale University, 1981.

Jain, M. P. “Error Analysis: Source, Cause and Significance." Error Analysis. Ed. J. C. Richards. London: Longman, 1974. 189-228.

James, Carl. "Deeper Contrastive Study." IRAL 7.2 (1969): 83-95.

Lado, Robert. Linguistics across Cultures. Ann Arbor: University of Michigan Press, 1957.

Mairs, Jane Lowenstein. "Stress Assignment in Interlanguage Phonology: An Analysis of the Stress System of Spanish Speakers Learning English." Linguistic Perspectives on Second Language Acquisition. Eds. Susan M. Gass and Jacquelin Schachter. Cambridge: University Press, 1989. 260-83.

Nemser, William. "Approximate Systems of Foreign Language Learners." Error Analysis. Ed. J. C. Richards. London: Longman, 1974: 55-63.

Nickel, Gerhard. "Some Controversies in Present-Day Error Analysis: Contrastive vs. Non-Contrastive Errors." IRAL 27.4 (1989): 293-305.

Odlin, Terence. Language Transfer: Crosslinguistic influence in language learning. Cambridge: University Press, 1989.

Olorode, Catherine S. "The Phonology of English Loanwords in Yoruba." Manuscript, 1992.

Selinker, Larry. "Interlanguage." Error Analysis: Perspectives on Second Language Acquisition.

Ed. J. C. Richards. London: Longmans, 1972. 31-53. .CA/EA/L: The Earliest Experimental Records." IRAL 27.4 (1989): 267-91.

Sridhar, S. N. "Contrastive Analysis, Error Analysis and Interlanguage: Three Phases of One Goal." Contrastive Linguistics and the Language Teacher. Ed. J. Fisiak. Oxford: Pergamon Press, 1981. 207-41.

Weinreich, Uriel. Languages in Contact: Findings and Problems. The Hague: Mouton, 1953. 